Article

\title{
Redox-Active Dysprosium Single-Molecule Magnet: Spectro-Electrochemistry and Theoretical Investigations
}

\author{
Guglielmo Fernandez Garcia ${ }^{1,2}$, Vincent Montigaud ${ }^{1}$, Lucie Norel ${ }^{1}$, Olivier Cador ${ }^{1}$, \\ Boris Le Guennic ${ }^{1, *} \mathbb{( \mathbb { D }}$, Federico Totti ${ }^{2} \mathbb{D}$ and Fabrice Pointillart ${ }^{1, * \mathbb{C}}$ \\ 1 Univ Rennes, CNRS, ISCR (Institut des Sciences Chimiques de Rennes)—UMR 6226, F-35000 Rennes, France \\ 2 Department of Chemistry Ugo Schiff and INSTM RU, University of Florence, 50019 Sesto Fiorentino, Italy \\ * Correspondence: boris.leguennic@univ-rennes1.fr (B.L.G.); fabrice.pointillart@univ-rennes1.fr (F.P.)
}

Received: 14 May 2019; Accepted: 31 July 2019; Published: 2 August 2019

check for updates

\begin{abstract}
The mononuclear single-molecule magnet $(\mathrm{SMM})\left[\mathrm{Dy}(\mathrm{tta})_{3}(\mathrm{~L})\right] \cdot \mathrm{C}_{6} \mathrm{H}_{14}(\mathbf{1})$ (where $\mathrm{tta}^{-}=$ 2-thenoyltrifluoroacetonate and $\mathrm{L}=4,5$-bis(propylthio)-tetrathiafulvalene-2-(2-pyridyl)benzimidazolemethyl-2-pyridine) was studied by spectro-electrochemistry. The resulting electronic spectra of the three oxidation states $1, \mathbf{1}^{+}$, and $\mathbf{1}^{2+}$ were rationalized by time-dependent density functional theory (TD-DFT) calculations starting from the DFT optimized structures. The modulation of the magnetic anisotropy of the Dy ${ }^{\text {III }}$ center upon oxidation was also inspected at the Complete Active Space Self-Consistent Field (CASSCF) level of calculation.
\end{abstract}

Keywords: dysprosium; tetrathiafulvalene; single-molecule magnet; spectro-electrochemistry; TD-DFT calculations; ab initio calculations

\section{Introduction}

Tetrathiafulvalene (TTF) is a well-known organic moiety successfully used in the elaboration of molecular conductors [1-7] and molecular switches [8-11] as well as solar-energy systems $[12,13]$ due to its ability to be a reversible, strong electron-donating species. To reach the design of multifunctional materials, the intense effort by chemists to combine the electronic conductivity with other physical properties is the focus of current research [14-17]. For instance, during the last decade, the "through bond" strategy, consisting in the functionalization of the TTF core with organic groups suitable for a coordination reaction with metal precursors [18-24], has been used to combine lanthanide magnetism and the attractive reversible redox properties of TTF derivatives [25-28]. Indeed, lanthanide ions possess a strong anisotropy and a large magnetic moment which make them good candidates for obtaining single-molecule magnets (SMMs) [29-37]. The motivation to design these new molecular objects is driven by their potential abilities to pave the way for a new generation of quantum devices, such as high-density data storage, quantum computing, and spintronics [38-43]. Thus, the combination of the lanthanides and TTF-based ligands led to exciting multiple properties SMMs [44-54]. Nevertheless, in these SMMs, TTF-based ligands are in their neutral state, and the examples of lanthanide coordination complexes involving radical cation TTF species are still very scarce $[55,56]$. In fact, there are only two examples to date of the direct comparison between two systems in which the TTF-based ligand is in its neutral and radical cation oxidation states to evaluate the effect of the oxidation on the magnetic properties $[57,58]$.

In the present article, we focus our attention on a mononuclear complex of formula $\left[\operatorname{Dy}(\mathrm{tta})_{3}(\mathbf{L})\right] \cdot \mathrm{C}_{6} \mathrm{H}_{14}$ (1) (where $\mathrm{tta}^{-}=$2-thenoyltrifluoroacetonate and $\mathbf{L}=4,5$-bis(propylthio)tetrathiafulvalene-2-(2-pyridyl)benzimidazole-methyl-2-pyridine) that displays SMM behavior with 
hysteresis at low temperature [59]. During the investigation of 1, its stability in $\mathrm{CH}_{2} \mathrm{Cl}_{2}$ solution was demonstrated by the study of the electronic spectrum and by measuring the hysteresis loop in frozen solution. Complex 1 was also at the origin of the highlight of isotopic effects on the relaxation time of the magnetization [60-62]. In spite of the plethora of studies performed on this system, no study was realized to probe the physical properties as well as the magnetic anisotropy after oxidation of the $\mathbf{L}$ ligand. Thus, to go one step further, we studied, herein, the electronic spectra of the first and second oxidation states of $\mathbf{1}$ (i.e., $\mathbf{1}^{+\cdot}$ and $\mathbf{1}^{2+}$, respectively) by spectro-electrochemistry followed by their rationalization upon TD-DFT (time-dependent density functional theory) calculations on the DFT optimized complexes. Finally, the influence of the oxidation on the magnetic properties was evaluated using Complete Active Space Self-Consistent Field/Restricted Active Space State-Interaction - Spin Orbit (CASSCF/RASSI-SO) calculations.

\section{Results and Discussion}

2.1. X-ray Structures of $\left[D y(t t a)_{3}(L)\right] \cdot C_{6} H_{14}(1) \cdot C_{6} H_{14}$, and DFT Optimized Structures of $\left[D y(t t a)_{3}(L)\right]\left(1_{\text {opt }}\right)$, $\left[D y(t t a)_{3}\left(L^{+\cdot}\right)\right]\left(1^{+\cdot}\right.$ opt $)$ and $\left[D y(t t a)_{3}\left(L^{2+}\right)\right]\left(1^{2+}{ }_{o p t}\right)$

The X-ray structure of $\mathbf{1}$ was refined and described in a previous work [60]. Briefly, the experimental molecular structure was used as starting point for the DFT optimized structures of $\left[\mathrm{Dy}(\mathrm{tta})_{3}(\mathbf{L})\right]\left(\mathbf{1}_{\text {opt }}\right)$, $\left[\mathrm{Dy}(\mathrm{tta})_{3}\left(\mathbf{L}^{+\cdot}\right)\right]\left(\mathbf{1}^{+\cdot}\right.$ opt $)$ and $\left[\mathrm{Dy}(\mathrm{tta})_{3}\left(\mathbf{L}^{2+}\right)\right]\left(\mathbf{1}^{2+}{ }_{\text {opt }}\right)$ (Figure S2). $\mathbf{1}$ consists in a mononuclear complex of Dy ${ }^{\mathrm{III}}$ (Figure 1 and Figure S3). The Dy ${ }^{\mathrm{III}}$ ion lies in an $\mathrm{N}_{2} \mathrm{O}_{6}$ coordination sphere with a square antiprism symmetry (SAPR-8 at 0.538 using SHAPE program [63]). The six oxygen atoms and two nitrogen atoms belong to three $\mathrm{hfac}^{-}$anions and the L ligand, respectively. The average Dy-N and Dy-O distances were $2.530 \AA$ and $2.333 \AA$, respectively. The central $\mathrm{C}=\mathrm{C}$ bond length $(1.347 \AA)$ and the non-planar conformation of the TTF core attest the neutrality of $\mathbf{L}$.

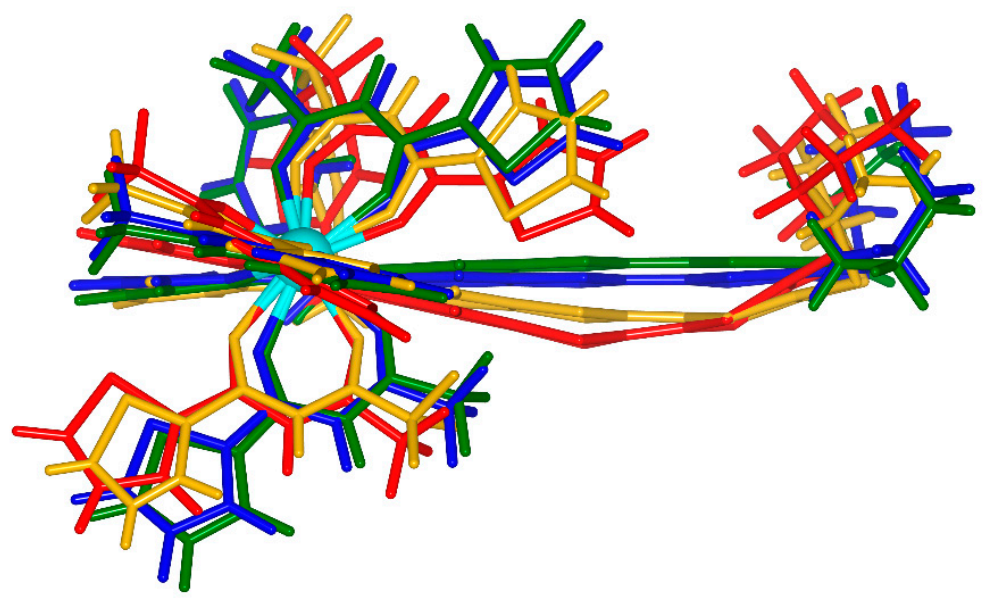

Figure 1. X-ray structure of $\mathbf{1}$ (yellow) and optimized structures for the different oxidation states $\mathbf{1}_{\mathbf{o p t}}$ (red), $\mathbf{1}^{+\cdot}$ opt (blue) and $\mathbf{1}^{2+}$ opt (green).

The DFT optimization of the structure of $\mathbf{1}$ led to a complete boat conformation for the TTF core (Figure 1 and Figure S2). While in the crystal structure, the pi-bonding between TTFs of neighboring molecules maintained the structure flat, in the absence of such interaction, the preferable minima for the ligand was a boated one. The Dy-N (2.551 $\AA$ ) and central $C=C(1.352 \AA)$ distances were found slightly longer than for the $X$-ray structure $(\mathrm{Dy}-\mathrm{N}=2.530(5) \AA$ and $\mathrm{C}=\mathrm{C}=1.347(9) \AA)$ while Dy-O $(2.322 \AA)$ was slightly shorter (Dy-O = 2.333(4) $\AA$ ). The symmetry of the Dy ${ }^{\mathrm{III}}$ surrounding remained $\mathrm{D}_{4 \mathrm{~d}}$ with a very similar distortion compare to the ideal square antiprism (0.526). The crystal packing of 1 was driven by the formation of head-to-tail dimers of complexes. One can remark that the bent ligand character is more pronounced in $\mathbf{1}_{\text {opt }}$ than for $\mathbf{1}$. It could be due to the fact that the flat ligand allows an optimal $\pi-\pi$ interaction in the head-to-tail dimers of complexes while for the optimized 
structure, the neighboring molecules are not taken into account in the calculations. Thus, the ligand is free to adopt such pronounced boat conformation in $\mathbf{1}_{\text {opt }}$.

After the mono- (Figure S4) and di-oxidation (Figure S5) of the TTF core, the optimized structures revealed an elongation of the central $C=C$ bond $\left(1.391 \AA\right.$ for $\mathbf{1}^{+\cdot}$ opt and $1.419 \AA$ for $\left.\mathbf{1}^{2+}{ }_{\text {opt }}\right)$ due to the loss of electrons. The latter led to an increase of the aromaticity of $\mathbf{L}$ due to the removal of electrons in the $\pi \mathrm{C}=\mathrm{C}$ and $\pi^{*} \mathrm{C}=\mathrm{S}$ molecular orbitals (MOs) (see $\mathbf{1}_{\mathrm{opt}}, \mathbf{1}^{+\cdot}$ opt, and $\mathbf{1}^{2+}{ }_{\text {opt }}$ ), and thus the TTF moiety became increasingly planar (Figure 1). The two previous observations are in agreement with the well-known consequences of a TTF core centered oxidation [64-66].

The decrease of the electron density on the TTF core affected the electron density of the benzoimidazole-pyridine moiety, too, and consequently the Dy-N (2.562 $\AA$ for $\mathbf{1}^{+}$opt and $2.318 \AA$ for $\left.\mathbf{1}^{2+}{ }_{\text {opt }}\right)$ and Dy-O (2.569 $\AA$ for $\mathbf{1}^{+}$opt and $2.315 \AA$ for $\left.\mathbf{1}^{2+}{ }_{\text {opt }}\right)$ distances were slightly longer and shorter than for the neutral species, respectively. The symmetry of the Dy ${ }^{I I I}$ surrounding remained $\mathrm{D}_{4 \mathrm{~d}}$ with a slightly higher distortion compared to the ideal square antiprism $\left(0.600\right.$ for $\mathbf{1}^{+\cdot}$ opt and 0.590 for $\mathbf{1}^{2+}$ opt $)$.

The X-ray structure of $\mathbf{1}$ and the three optimized structures demonstrated the integrity of the coordination complexes for all the oxidation states of the TTF core.

\subsection{Electrochemical Properties}

The redox properties of the ligand $\mathbf{L}$ and complex $\mathbf{1}$ were investigated by cyclic voltammetry. The cyclic voltammograms for $\mathbf{L}$ and $\mathbf{1}$ showed two mono-electronic oxidations at $0.504 \mathrm{~V}$ (reversible) and $0.912 \mathrm{~V}$ (quasi-reversible) for $\mathrm{L}$ and $0.519 \mathrm{~V}$ (reversible) and $0.941 \mathrm{~V}$ (quasi-reversible) for $\mathbf{1}$. They correspond successively to the formation of the TTF fragment radical cation and dication (Figures S6 and S7). Oxidation potentials were shifted to higher positive values relative to the parent TTF due to partial electron transfer from the donor (TTF) to the benzoimidazole-pyridine acceptor moiety. More interesting is the slight shifts to higher oxidation potentials from $\mathbf{L}$ to $\mathbf{1}$ which illustrate the weak decrease of electron density on the TTF core after coordination. The electrochemical properties attest to the redox-activity of $\mathbf{L}$ and the corresponding complex. Such redox properties are required to perform spectro-electrochemistry and give crucial information on the potential values which must be applied (see next section).

\subsection{Photo-Physical and Spectro-Plectrochemical Properties}

The electronic properties of the complex were investigated in its neutral state (1), in its first $\left(\mathbf{1}^{+\cdot}\right)$ and second $\left(\mathbf{1}^{2+}\right)$ oxidized states during electrochemical oxidation in the 9000 to $27,000 \mathrm{~cm}^{-1}$ energy range.

The electronic spectrum of $\mathbf{1}$ in this energy range was mainly composed of one intense absorption band centered at $23200 \mathrm{~cm}^{-1}$ (red lines in Figure 2 and red decomposition in Figure 3a) which has been identified as intra-ligand charge transfer (ILCT) from the TTF fragment to both bzip and 2-thenoyltrifluoroacetonate $\left(\mathrm{tta}^{-}\right)$units (Table 1) [59]. The modification of the electronic spectrum was further studied during electrochemical oxidation in an optically transparent thin-layer electrochemical (OTTLE) cell. The applied potential of the device was firstly set between the first and second oxidation potentials of $\mathbf{1}$ to study the radical cation form $\mathbf{1}^{+\cdot}$. Under an applied potential of $0-0.7 \mathrm{~V}$ (Figure 2a), several new absorption bands appeared (Figure $2 b$ ). 

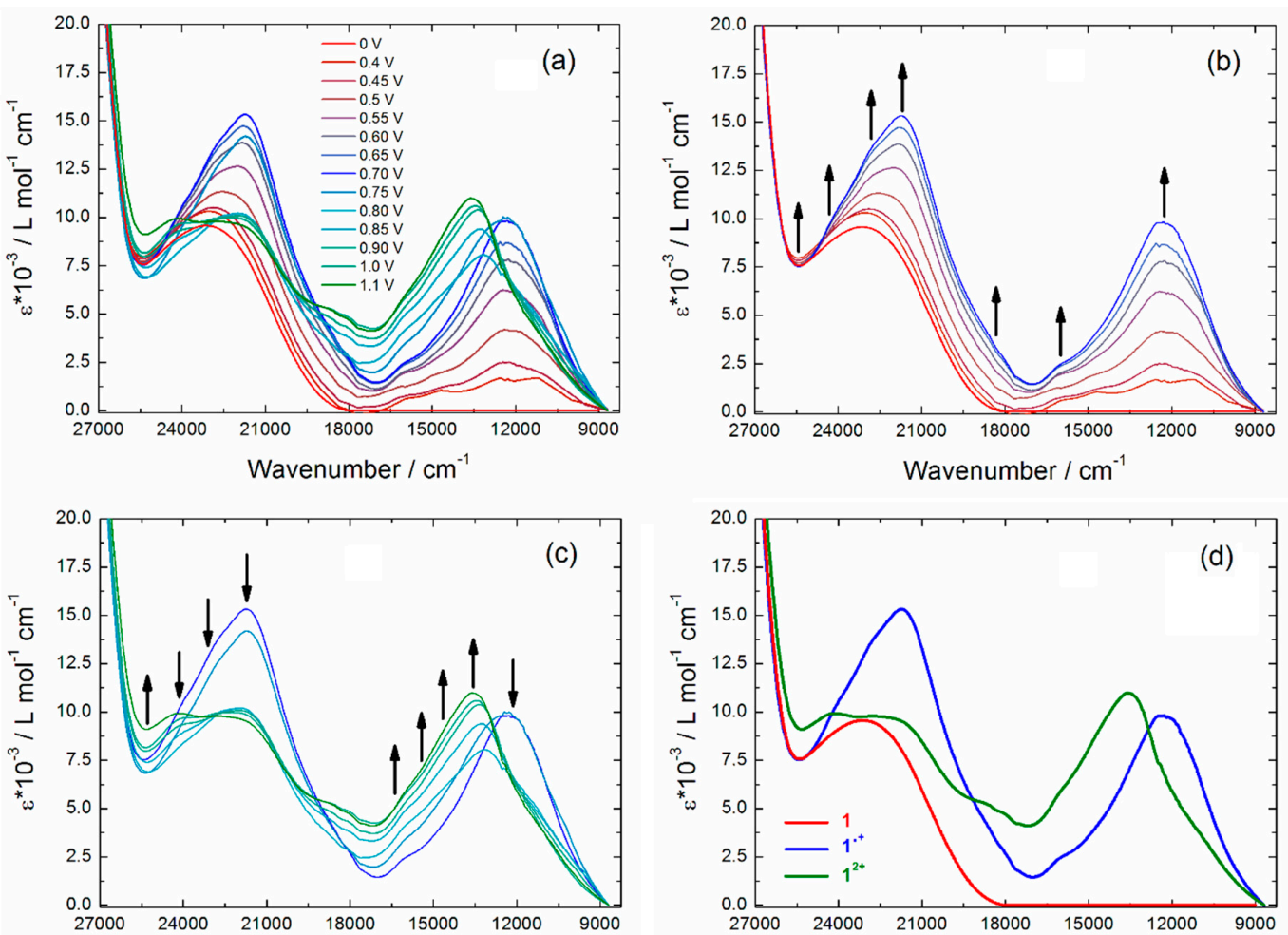

Figure 2. (a) Absorption spectra for $\mathbf{1}$ in the visible-NIR range during its first and second oxidation in $0.2 \mathrm{M} \mathrm{n}-\mathrm{Bu}_{4} \mathrm{NPF}_{6} / \mathrm{CH}_{2} \mathrm{Cl}_{2}$. (b) Absorption spectra and spectroscopic changes for 1 in the visible-NIR range during its first oxidation in $0.2 \mathrm{Mn}-\mathrm{Bu}_{4} \mathrm{NPF}_{6} / \mathrm{CH}_{2} \mathrm{Cl}_{2}$. (c) Absorption spectra and spectroscopic changes for 1 in the visible-NIR range during its second oxidation in $0.2 \mathrm{Mn}-\mathrm{Bu}_{4} \mathrm{NPF}_{6} / \mathrm{CH}_{2} \mathrm{Cl}_{2}$. (d) Absorption spectra for $\mathbf{1}$ (red curve), $\mathbf{1}^{+\bullet}$ (blue curve), and $\mathbf{1}^{2+}$ (green curve).
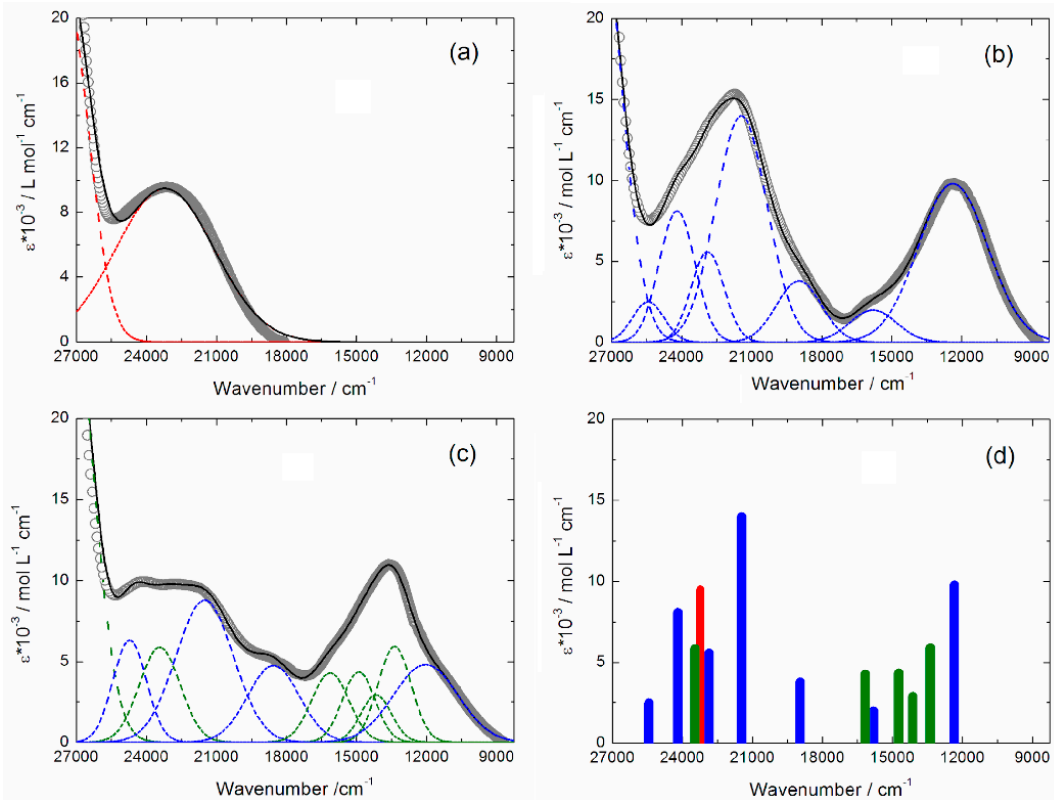

Figure 3. (a) Experimental UV-visible absorption spectrum of $\mathbf{1}$ in $\mathrm{CH}_{2} \mathrm{Cl}_{2}$ solution (open grey circles), respective Gaussian decompositions (dashed red lines), and best fit (full black line, $R^{2}=9980$ ). (b) Experimental $\mathrm{UV}$-visible absorption spectrum of $\mathbf{1}^{+\cdot}$ in $\mathrm{CH}_{2} \mathrm{Cl}_{2}$ solution (open grey circles), respective Gaussian decompositions (dashed red lines), and best fit (full black line, $\mathrm{R}^{2}=0.9974$ ). (c) Experimental UV-visible absorption spectrum of $\mathbf{1}^{2+}$ in $\mathrm{CH}_{2} \mathrm{Cl}_{2}$ solution (open grey circles), respective Gaussian decompositions (dashed red lines), and best fit (full black line, $\left.\mathrm{R}^{2}=0.9965\right)$. (d) Experimental positions and intensities of the Gaussian decompositions for $\mathbf{1}$ (red sticks), $\mathbf{1}^{+\cdot}$ (blue sticks), and $\mathbf{1}^{2+}$ (green sticks). 
Table 1. Experimental and time-dependent density functional theory (TD-DFT) calculated excitation energies and main compositions of the low-lying electronic transitions for $\mathbf{1}, \mathbf{1}^{+}$, and $\mathbf{1}^{2+}$. In addition, the charge transfer and the pure intramolecular transitions are reported. ID, IA, H, and L represent the intramolecular tetrathiafulvalene (TTF) (Donor) or intramolecular bzip (Acceptor) transitions, and the highest occupied molecular orbital (HOMO) and lowest unoccupied molecular orbital (LUMO), respectively. Therefore, ILCT stands for intra-ligand charge transfer. The theoretical values are evaluated at the $\mathrm{PCM}\left(\mathrm{CH}_{2} \mathrm{Cl}_{2}\right)-\mathrm{PBE} 0 / \mathrm{SVP}$ level of approximation.

\begin{tabular}{|c|c|c|c|c|c|c|}
\hline & $\begin{array}{l}\text { Exp. Energy } \\
\left(\mathrm{cm}^{-1}\right)\end{array}$ & $\begin{array}{l}\text { Theo Energy } \\
\left(\mathrm{cm}^{-1}\right)\end{array}$ & Osc. & Type & Assignment & Transition \\
\hline \multirow{3}{*}{1} & 23200 & 21,044 & 0.23 & & $\pi_{\mathrm{TTF}} \rightarrow \pi_{\text {bzip }}^{*}$ & $\mathrm{H} \rightarrow \mathrm{L}(91 \%)$ \\
\hline & 23,200 & 21,356 & 0.04 & ILCT & $\pi_{\mathrm{TTF}} \rightarrow \pi_{\mathrm{tta}}^{*}$ & $\mathrm{H} \rightarrow \mathrm{L}+1(72 \%)$ \\
\hline & 12,300 & 12,475 & 0.35 & ID ILCT & $\begin{array}{l}\pi_{\mathrm{TTF}} \rightarrow \pi^{*} \mathrm{TTF} \\
\pi_{\mathrm{tta}} \rightarrow \pi^{*} \mathrm{TTF}\end{array}$ & $\begin{array}{l}\mathrm{H}-3_{\beta} \rightarrow \mathrm{L}_{\beta}(75 \%) \\
\mathrm{H}-2_{\beta} \rightarrow \mathrm{L}_{\beta}(21 \%)\end{array}$ \\
\hline \multirow{2}{*}{$1^{+\cdot}$} & 15,800 & 18,491 & 0.02 & ID & $\pi_{\mathrm{TTF}} \rightarrow \pi^{*} \mathrm{TTF}$ & $\begin{array}{c}\mathrm{H}-12_{\beta} \rightarrow \mathrm{L}_{\beta}(30 \%) \\
\mathrm{H}-8_{\beta} \rightarrow \mathrm{L}_{\beta}(54 \%)\end{array}$ \\
\hline & 18,900 & 19,844 & 0.02 & ID & $\pi_{\mathrm{TTF}} \rightarrow \pi^{*} \mathrm{TTF}$ & $\begin{array}{c}\mathrm{H}-12_{\beta} \rightarrow \mathrm{L}_{\beta}(49 \%) \\
\mathrm{H}-8_{\beta} \rightarrow \mathrm{L}_{\beta}(25 \%)\end{array}$ \\
\hline \multirow{13}{*}{$1^{2+}$} & 21,500 & 22,325 & 0.20 & ILCT & $\pi_{\mathrm{TTF}} \rightarrow \pi^{*}$ bzip & $\mathrm{H}_{\alpha} \rightarrow \mathrm{L}_{\alpha}(49 \%)$ \\
\hline & 22,900 & 23,823 & 0.06 & ID & $\pi_{\mathrm{TTF}} \rightarrow \pi^{*} \mathrm{TTF}$ & $\begin{array}{c}\mathrm{H}_{\alpha} \rightarrow \mathrm{L}+5_{\alpha}(37 \%) \\
\mathrm{H}_{\alpha} \rightarrow \mathrm{L}+6_{\alpha}(23 \%) \\
\mathrm{H}-6_{\alpha} \rightarrow \mathrm{L}_{\alpha}(12 \%)\end{array}$ \\
\hline & 24,200 & 24,449 & 0.22 & IA ID ILCT & $\begin{array}{l}\pi_{\text {bzip }} \rightarrow \pi^{*} \text { bzip } \\
\pi_{\text {TTF }} \rightarrow \pi^{*} \text { TTF } \\
\pi_{\text {TTF }} \rightarrow \pi^{*} \text { bzip }\end{array}$ & $\begin{array}{c}\mathrm{H}-4_{\alpha} \rightarrow \mathrm{L}+1_{\alpha}(15 \%) \\
\mathrm{H}_{\alpha} \rightarrow \mathrm{L}+6_{\alpha}(21 \%) \\
\mathrm{H}_{\alpha} \rightarrow \mathrm{L}_{\alpha}(20 \%)\end{array}$ \\
\hline & 25,400 & 25,732 & 0.12 & ID & $\pi_{\mathrm{TTF}} \rightarrow \pi^{*} \mathrm{TTF}$ & $\begin{array}{l}\mathrm{H}_{\alpha} \rightarrow \mathrm{L}+5_{\alpha}(25 \%) \\
\mathrm{H}_{\alpha} \rightarrow \mathrm{L}+6_{\alpha}(21 \%)\end{array}$ \\
\hline & 12,000 * & 12,475 & 0.35 & ID ILCT & $\begin{array}{l}\pi_{\mathrm{TTF}} \rightarrow \pi^{*} \mathrm{TTF} \\
\pi_{\mathrm{tta}} \rightarrow \pi^{*} \mathrm{TTF}\end{array}$ & $\begin{array}{l}\mathrm{H}-3_{\beta} \rightarrow \mathrm{L}_{\beta}(75 \%) \\
\mathrm{H}-2_{\beta} \rightarrow \mathrm{L}_{\beta}(21 \%)\end{array}$ \\
\hline & 13,400 & 13,620 & 0.66 & ID ILCT & $\pi_{\mathrm{L}} \rightarrow \pi^{*} \mathrm{TTF}$ & $\begin{aligned} H-4 \rightarrow L & (69 \%)\end{aligned}$ \\
\hline & 14,100 & 14,085 & 0.19 & ILCT & $\begin{array}{l}\pi_{\mathrm{tta}} \rightarrow \pi^{*} \mathrm{TTF} \\
\pi_{\mathrm{L}} \rightarrow \pi^{*} \mathrm{TTF}\end{array}$ & $\begin{array}{c}\mathrm{H}-5 /-6 \rightarrow \mathrm{L}(65 \%) \\
\mathrm{H}-4 \rightarrow \mathrm{L}(69 \%)\end{array}$ \\
\hline & 14,900 & 14,689 & 0.11 & ILCT & $\pi_{\mathrm{tta}} \rightarrow \pi^{*} \mathrm{TTF}$ & $\mathrm{H}-5 /-8 \rightarrow \mathrm{L}(65 \%)$ \\
\hline & 16,200 & 15,063 & 0.05 & ILCT & $\pi_{\mathrm{tta}} \rightarrow \pi^{*} \mathrm{TTF}$ & H-5/-6/-9/-10 $\rightarrow$ L (66\%) \\
\hline & 18,600 * & 19,844 & 0.02 & ID & $\pi_{\mathrm{TTF}} \rightarrow \pi^{*} \mathrm{TTF}$ & $\begin{array}{c}\mathrm{H}-12_{\beta} \rightarrow \mathrm{L}_{\beta}(49 \%) \\
\mathrm{H}-2_{\beta} \rightarrow \mathrm{L}_{\beta}(25 \%)\end{array}$ \\
\hline & $21,500 *$ & $22,32523,823$ & $\begin{array}{l}0.20 \\
0.06\end{array}$ & ILCT ID & $\begin{array}{l}\pi_{\mathrm{TTF}} \rightarrow \pi_{\text {bzip }}^{*} \\
\pi_{\mathrm{TTF}} \rightarrow \pi^{*} \mathrm{TTF}\end{array}$ & $\begin{array}{c}\mathrm{H}_{\alpha} \rightarrow \mathrm{L}_{\alpha}(49 \%) \\
\mathrm{H}_{\alpha} \rightarrow \mathrm{L}+5_{\alpha}(37 \%) \\
\mathrm{H}_{\alpha} \rightarrow \mathrm{L}+6_{\alpha}(23 \%)\end{array}$ \\
\hline & 23,500 & 23,769 & 0.02 & ID & $\pi_{\mathrm{TTF}} \rightarrow \pi^{*} \mathrm{TTF}$ & $\mathrm{H}-20 \rightarrow \mathrm{L}(95 \%)$ \\
\hline & $24,700 *$ & $24,44925,732$ & 0.220 .12 & IA ID ILCT & $\begin{array}{l}\pi_{\text {bzip }} \rightarrow \pi^{*} \text { bzip } \\
\pi_{\text {TTF }} \rightarrow \pi^{*} \text { TTF } \\
\pi_{\text {TTF }} \rightarrow \pi^{*} \text { bzip }\end{array}$ & $\begin{array}{c}\mathrm{H}-6_{\alpha} \rightarrow \mathrm{L}_{\alpha}(12 \%) \\
\mathrm{H}-4_{\alpha} \rightarrow \mathrm{L}+1_{\alpha}(15 \%) \\
\mathrm{H}_{\alpha} \rightarrow \mathrm{L}+5 /+6_{\alpha}(42 \%) \\
\mathrm{H}_{\alpha} \rightarrow \mathrm{L}_{\alpha}(20 \%)\end{array}$ \\
\hline
\end{tabular}

* These absorption contributions come from the $\mathbf{1}^{+\cdot}$.

The resulting electronic spectrum of $\mathbf{1}^{+\cdot}$ is depicted in Figure $3 b$, and it was decomposed in seven contributions. The three lowest-energy bands are identified as intra-donor (ID) excitations involving the radical cation $\mathrm{TTF}^{+}$core. At this point, it is worth noting that the lowest-energy band centered at $12,300 \mathrm{~cm}^{-1}$ (calculated at $12,475 \mathrm{~cm}^{-1}$, Figure 4) is also composed of an intra-ligand charge transfer (ILCT) excitation (HOMO-2 $\beta \rightarrow$ LUMO $\beta$, Figure 5 and Table 1 ) starting from the $\mathrm{tta}^{-}$ancillary ligand to the $\mathrm{TTF}^{+}$. Such ILCT excitations are allowed because of (i) the strong decrease of the donating character of the radical-cation $\mathrm{TTF}^{+\cdot}$ core compared to the neutral TTF core $[67,68]$ and (ii) the stronger accepting character of the $\mathrm{tta}^{-}$anions than bzip moiety as attested by the nature of the ILCT in $\mathbf{1}$ and as already observed in other TTF-based systems involving tta $^{-}$anions [59]. Then four new additional absorption bands appeared after oxidation of the complex at 21,500, 22,900, 24,200, and 25,400 cm (Figures 2-4) which are attributed to $\pi \rightarrow \pi^{*}$ intra-TTF ${ }^{+*}$ (ID) excitations (HOMO $\alpha \rightarrow \mathrm{LUMO}+5 /$ $+6 \alpha$, Figure 5 and Table 1 ) and to the HOMO $\alpha \rightarrow$ LUMO $\alpha$ ILCT. The HOMO $\alpha$ and LUMO $\alpha$ are respectively centered $\mathrm{TTF}^{+\cdot}$ and bzip orbitals (Figure 5), and consequently the $\mathrm{HOMO} \alpha \rightarrow \mathrm{LUMO} \alpha$ ILCT of $\mathbf{1}^{+\cdot}\left(21500 \mathrm{~cm}^{-1}\right.$, Table 1$)$ is analogous to the HOMO $\rightarrow$ LUMO ILCT of $\mathbf{1}\left(23,200 \mathrm{~cm}^{-1}\right.$, Table 1$)$. Both experimental (Figures $2 \mathrm{~d}$ and $3 \mathrm{a}, \mathrm{b}$ ) and calculated (Figure 3 ) absorption spectra are in perfect 
agreement. The reversibility of the first electrochemical oxidation of $\mathbf{1}$ was checked showing an almost complete reversible process (Figure S8).

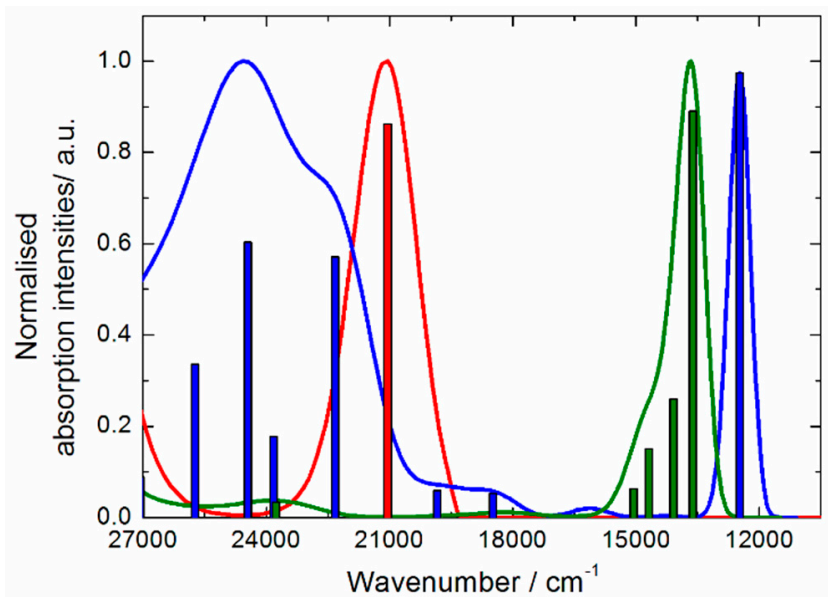

Figure 4. Theoretical absorption spectra for $\mathbf{1}_{\text {opt }}$ (red curve), $\mathbf{1}^{+}$opt (blue curve), and $\mathbf{1}^{2+}$ opt (green curve); the bars represent the mean contribution of the absorption spectra that are listed in Table 1.
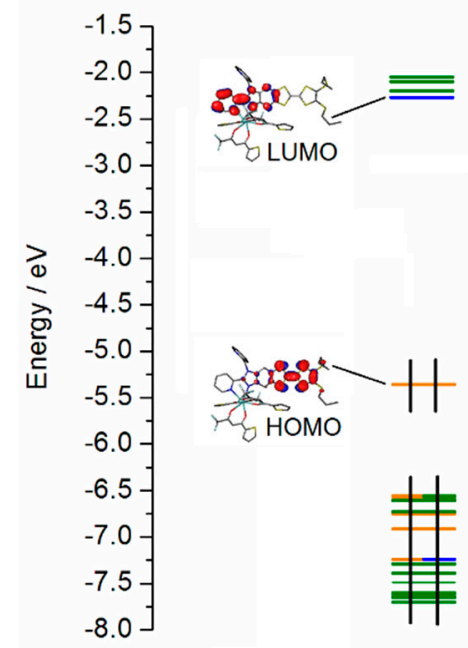

$\left(1_{\text {opt }}\right)$
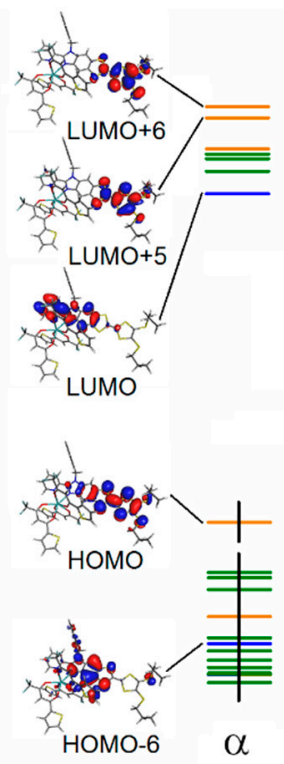

$\alpha$

$\left(1_{\text {opt }}^{+\cdot}\right.$

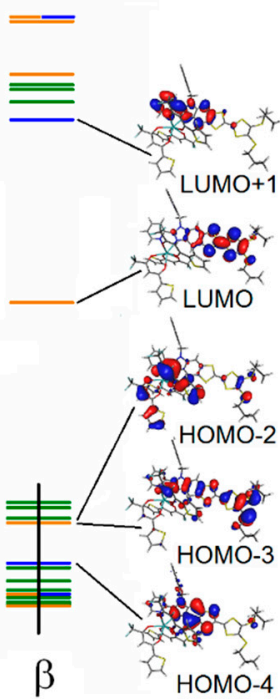

$\left(1_{\mathrm{opt}}^{2+}\right)$

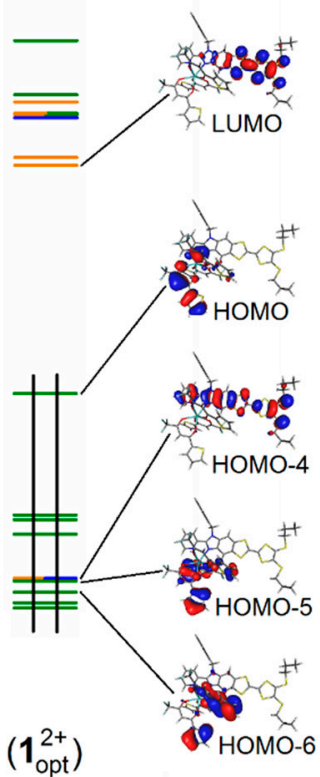

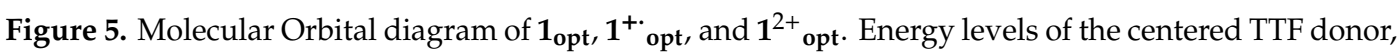
bzip acceptor, and $\mathrm{tta}^{-}$anion are represented in orange, blue, and green, respectively. Full vertical black lines represent the electrons of the occupied orbitals.

Spectroscopic changes under an applied potential of 0.75 to $1.10 \mathrm{~V}$ are depicted in Figure 2a,c. Comparison of the experimental (Figure $3 \mathrm{c}$ ) and calculated absorption spectra (Figure 4 ) leads to the conclusion that even at $1.10 \mathrm{~V}$ a mixture of the $\mathbf{1}^{+\cdot}$ (blue decompositions) and $\mathbf{1}^{2+}$ (green decompositions) species is observed. Unfortunately, in our experimental conditions, the application of higher potentials led to irreversible decomposition of the species. Nevertheless, the absorption contributions attributing to $\mathbf{1}^{2+}$ could be determined. Thus, in the energy range of 9000 to $27,000 \mathrm{~cm}^{-1}$, five decompositions have been identified (Figure 3c,d). The four absorption bands centered at 13,400, 14,100, 14,900, and $16,200 \mathrm{~cm}^{-1}$ and calculated at 13620, 14085, 14689, and $15063 \mathrm{~cm}^{-1}$ (Table 1) are attributed to ILCT between the highest occupied molecular orbital (HOMO)-4 (fully delocalized orbital on the whole ligand) and the lowest unoccupied molecular orbital (LUMO) (centered on the dicationic TTF $^{2+}$ 
core) and ILCT between $\mathrm{tta}^{-}$centered orbital and the LUMO. At higher energy, an ID HOMO-20 $\rightarrow$ $\operatorname{LUMO}\left(23,500 \mathrm{~cm}^{-1}\right)$ excitation was also identified. The electronic spectrum of $\mathbf{1}^{2+}$ was composed of excitations involving the LUMO as the accepting orbital because of the drastic decrease of the donating character of the dicationic $\mathrm{TTF}^{2+}$ core compared to the neutral TTF and radical cationic $\mathrm{TTF}^{+}$cores. In the fully oxidized $\mathbf{1}^{2+}$ compound, the tta ${ }^{-}$ancillary ligands can be seen as the best accepting groups of the system. Finally, the HOMO- 4 for $\mathbf{1}^{2+}$ is the equivalent of the HOMO for $\mathbf{1}$ and $\mathbf{1}^{+\cdot}$.

Interestingly, the delocalization of these highest-energy TTF-centered orbitals is proportional to the aromaticity of the ligand. Thus, the HOMO is totally centered on the TTF core (Figure 5), which adopts a boat conformation (Figure 1), in $\mathbf{1}$; the HOMO is mainly centered on the $\mathrm{TTF}^{+\cdot}$ core, which is almost planar (Figure 1), in $\mathbf{1}^{\mathbf{+}}$ and the HOMO is totally delocalized on the whole $\mathbf{L}$ ligand, which is totally flat (Figure 1 ), in $\mathbf{1}^{2+}$.

The second oxidation of $\mathbf{1}$ is badly reversible (Figure S9) in agreement with the electrochemical properties, which show only a quasi-reversible second oxidation at $0.94 \mathrm{~V}$ (Figure S7).

\subsection{Magnetic Properties}

SA-CASSCF/RASSI-SO calculations were performed for each oxidation state of $\mathbf{1}$ to tentatively evaluate the potential impact of the oxidation of the TTF core on the magnetic anisotropy of the Dy III center. Calculations demonstrated that the axial character of the magnetic anisotropy tensor of the almost pure ground Kramers doublet $\mathrm{M}_{\mathrm{J}}= \pm 15 / 2$ is conserved after the TTF-centered oxidation (Table S1). The calculated $\mathrm{g}_{\mathrm{zz}}$ components are equal to 19.52 for $\mathbf{1}, 19.56$ for $\mathbf{1}_{\text {opt }}, 19.57$ for $\mathbf{1}^{\mathbf{+}}{ }_{\text {opt }}$, and 19.45 for $\mathbf{1}^{2+}$ opt (Table S1). Whatever the oxidation state, the main component of the magnetic anisotropy $\left(\mathrm{g}_{\mathrm{zz}}\right)$ remains oriented perpendicular to the plane formed by the nitrogen atoms of the benzo-imidazole-2-pyridine moiety as expected for an oblate ion (Figure S10). Finally, the energy splitting of the ${ }^{6} \mathrm{H}_{15 / 2}$ ground state is almost not affected by the oxidation process (Figure S11). In other words, the oxidation of the TTF core has presumably no influence on the magnetic anisotropy from a molecular perspective. However, from a computational perspective, these calculations cannot completely exclude an influence of the oxidation on the magnetism. Taking the $\mathbf{1}^{+\cdot}$ opt as an example, to affirm this, it would be necessary to perform a calculation on an active space that includes at least the metal ion, the electron on the TTF, and all its correlated orbitals. However, such calculations demand is, for now, prohibitive. In any case, the observations made from our state-of-the-art calculations are in agreement with what has been observed in previously studied systems highlighting that to obtain a redox-magnetic switching, the organic radical should be directly connected to the lanthanide ion [69-71].

\section{Materials and Methods}

\subsection{Synthesis. General Procedures and Materials}

All solvents were dried using standard procedures. 4,5-bis(propylthio)-tetrathiafulvalene-2-(2pyridyl)benzimidazole-methyl-2-pyridine ligand (L) [72], Dy(tta) $)_{3} \cdot 2 \mathrm{H}_{2} \mathrm{O}$ [73] precursor and $\left[\mathrm{Dy}(\mathrm{tta})_{3}(\mathbf{L})\right] \cdot \mathrm{C}_{6} \mathrm{H}_{14}(\mathbf{1})[59]$ compound were prepared according to the literature procedure. All the reagents were purchased from Aldrich and Alfa Aesar Co. Ltd. and were used without further purification.

\subsection{Physical Measurements}

Cyclic voltammetry was carried out in $\mathrm{CH}_{2} \mathrm{Cl}_{2}$ solution, containing $0.1 \mathrm{M}\left(\mathrm{C}_{4} \mathrm{H}_{9}\right)_{4} \mathrm{NPF}_{6}$ as supporting electrolyte. Voltammograms were recorded at $100 \mathrm{mV} \mathrm{s}^{-1}$ at a platinum disk electrode. The potentials were measured versus a saturated calomel electrode (SCE). Optical spectra were measured using the $\mathrm{KBr}$ disk method on Perkin-Elmer 1600 Series FT-IR (resolution $4 \mathrm{~cm}^{-1}$ ) for infrared (IR). Absorption spectra were recorded on a Varian Cary 5000 UV-Visible-NIR spectrometer. Electrochemical studies were carried out under argon using an Eco Chemie Autolab PGSTAT 
30 potentiostat $\left(\mathrm{CH}_{2} \mathrm{Cl}_{2}, 0.2 \mathrm{M} \mathrm{Bu}_{4} \mathrm{NPF}_{6}\right)$, the working electrode was a Pt disk, and ferrocene was the internal reference. Visible spectro-electrochemistry (SEC) experiments were performed at $20{ }^{\circ} \mathrm{C}$, under argon, with a homemade optically transparent thin-layer electrochemical (OTTLE) cell, path length $=1 \mathrm{~mm}$, using a Varian CARY 5000 spectrometer and an EG \& G PAR Model 362 potentiostat. A Pt mesh was used as the working electrode, a Pt wire was used as the counter electrode, and an Ag wire was used as a pseudo reference electrode. The electrodes were arranged in the cell such that the $\mathrm{Pt}$ mesh was in the optical path of the quartz cell. The anhydrous freeze-pump-thaw degassed sample-electrolyte solution $\left(0.2 \mathrm{M} n-\mathrm{Bu}_{4} \mathrm{NPF}_{6}\right)$ was cannula-transferred under argon into the cell previously thoroughly deoxygenated.

\subsection{Computational Details}

DFT geometry optimizations and TD-DFT excitation energy calculations of the $\mathrm{Y}^{\mathrm{III}}$ analogs of the corresponding complexes $\mathbf{1}_{\text {opt }}, \mathbf{1}^{+\cdot}$ opt, and $\mathbf{1}^{2+}$ opt were carried out with the Gaussian 09 (revision A.02) package [74] employing the PBE0 hybrid functional $[75,76]$. The "Stuttgart/Dresden" basis sets and effective core potentials were used to describe the yttrium atom [77], whereas all other atoms were described with the SVP basis sets [78]. The first 50 monoelectronic excitations were calculated. In all steps, a modeling of bulk solvent effects (solvent = dichloromethane) was included through the Polarisable Continuum Model (PCM) [79], using a linear-response non-equilibrium approach for the TD-DFT step [80,81]. Molecular orbitals were sketched using the Gabedit graphical interface [82]. Wavefunction-based calculations were carried out on the experimental molecular structure of $\mathbf{1}$ and on the DFT optimized structures $\mathbf{1}_{\mathbf{o p t}}, \mathbf{1}^{\mathbf{+}}$ opt , and $\mathbf{1}^{2+}{ }_{\text {opt }}$ by using the SA-CASSCF/RASSI-SO approach, as implemented in the MOLCAS quantum chemistry package (versions 8.0) [83]. In this approach, the relativistic effects are treated in two steps based on the Douglas-Kroll Hamiltonian. First, the scalar terms were included in the basis-set generation and were used to determine the spin-free wavefunctions and energies in the complete active space self-consistent field (CASSCF) method [84]. Next, spin-orbit coupling was added within the restricted-active-space-state-interaction (RASSI-SO) method, which uses the spin-free wavefunctions as basis states $[85,86]$. The resulting wavefunctions and energies are used to compute the magnetic properties and g-tensors of the lowest states from the energy spectrum by using the pseudo-spin $S=\frac{1}{2}$ formalism in the SINGLE-ANISO routine $[87,88]$. Cholesky decomposition of the bielectronic integrals was employed to save disk space and speed-up the calculations [89]. In all calculations, the active space of the self-consistent-field (CASSCF) method consisted of the nine $4 \mathrm{f}$ electrons of the Dy ${ }^{\mathrm{III}}$ ion spanning the seven $4 \mathrm{f}$ orbitals, i.e., CAS(9,7)SCF. State-averaged (SA-)CASSCF calculations were performed for all of the sextets (21 roots), all of the quadruplets (224 roots), and 300 out of the 490 doublets (due to hardware limitations) of the Dy ${ }^{\text {III }}$ ion. Twenty-one sextets, 128 quadruplets, and 107 doublets were mixed through spin-orbit coupling in RASSI-SO. All atoms were described using the Relativistic (semi-)Core Correlation - Atomic Natural Orbital (ANO-RCC) basis sets [90-92]. The following contractions were used: [8s7p4d3f2g1h] for Dy, [4s3p2d1f] for the O and N atoms, [3s2p1d] for the C and F atoms, [4s3p1d] for the S atoms, and [2s1p] for the $\mathrm{H}$ atoms.

\section{Conclusions}

To conclude, we have shown by spectro-electrochemistry that it is possible to form reversibly the radical cation and the dicationic species of a well-known redox-active SMM. The electronic spectra of the three compounds $1, \mathbf{1}^{+\cdot}$, and $\mathbf{1}^{2+}$ were experimentally decomposed and rationalized by TD-DFT calculations. Upon oxidation, the donating character of the TTF core decreased, playing the double role of electron donator and acceptor in $\mathbf{1}^{+\cdot}$, until becoming an electron-acceptor in $\mathbf{1}^{2+}$. Consequently, the lowest-energy electronic transitions were identified as TTF $\rightarrow$ bzip ILCT for 1 , TTF $\rightarrow$ TTF ID for $\mathbf{1}^{+\cdot}$, and tta $\rightarrow$ TTF ILCT for $\mathbf{1}^{2+}$. Finally, ab initio calculations demonstrated that the magnetic anisotropy of the Dy ${ }^{\mathrm{III}}$ is kept under the oxidation process in at the molecular level paving the route to design conducting SMM with these systems. Efforts to obtain single crystals of the oxidized systems and measurements of electronic conductivity are still in progress in our laboratory. 
Supplementary Materials: The following are available online at http://www.mdpi.com/2312-7481/5/3/46/s1, Figure S1. X-ray structure of $\mathbf{1}$ and optimized structures for the different oxidation states $\left(\mathbf{1}_{\text {opt }}, \mathbf{1}^{+}{ }_{\text {opt }},{ }_{\text {and }} \mathbf{1}^{2+}\right.$ opt $)$; Figure S2. Experimental X-ray structure of 1. n-hexane molecule of crystallization and hydrogen atoms are omitted for clarity; Figure S3. Optimized structure of 1; Figure S4. Optimized structure of $\mathbf{1}^{+\cdot}$. Figure S5. Optimized structure of $\mathbf{1}^{2+}$; Figure S6. Cyclic voltammograms of $\mathbf{L}$ (gray line) and $\mathbf{1}$ (black line) in $\mathrm{CH}_{2} \mathrm{Cl}_{2}$ at a scan rate of $100 \mathrm{mV} \cdot \mathrm{s}^{-1}$. The potentials were measured vs. a saturated calomel electrode (SCE) with $\mathrm{Pt}$ wires as working and counter electrodes; Figure S7. Cyclic voltammograms of $\mathbf{1}$ (black line, ten first cycles) in $\mathrm{CH}_{2} \mathrm{Cl}_{2}$ at a scan rate of $100 \mathrm{mV} \cdot \mathrm{s}^{-1}$. The potentials were measured vs. a saturated calomel electrode (SCE) with Pt wires as working and counter electrodes; Figure S8. Initial absorption spectra of $\mathbf{1}$ (red line), after oxidation under a $0.7 \mathrm{~V}$ applied currant $\mathbf{1}^{+\cdot}$ (blue line), and after switching off the applied current for 20 min (dashed red line). The full red line is recovered after 35 minutes; Figure S9. Initial absorption spectra of $\mathbf{1}$ (red line), after oxidation under a $1.1 \mathrm{~V}$ applied currant $\mathbf{1}^{2+}$ (green line) and after switching off the applied current for 20 min (dashed red line); Figure S10. Representation of the calculated local ground state magnetic anisotropy axes for the complexes $\mathbf{1}$,

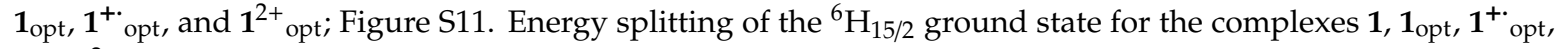
and $\mathbf{1}^{2+}{ }_{\text {opt}}$; Table S1. Main components of the magnetic anisotropy g-tensor ( $g_{X X}, g_{Y Y}$ and $\left.g_{Z Z}\right)$ and wavefunction composition of the ground state of $\mathbf{1}, \mathbf{1}_{\mathrm{opt}}, \mathbf{1}^{+\cdot}$ opt, and $\mathbf{1}^{2+}$ opt.

Author Contributions: F.P. performed the coordination chemistry; L.N. performed the spectro-electrochemistry; G.F.G., V.M., and B.L.G. performed the DFT, TD-DFT, and ab initio calculations. F.T. discussed the idea and the results and commented on the manuscript. F.P., O.C., and B.L.G. conceived and designed the experiments and contributed to the writing of the article.

Funding: This work was supported by Région Bretagne, Rennes Métropole, CNRS, Université de Rennes 1, the European Commission through the ERC-CoG 725184 MULTIPROSMM (project n. 725184) and ERC-AdG 267746 MolNanoMas (project no. 267746) and the ANR (ANR-13-BS07-0022-01) for financial support. B.L.G. and G.F.G. thank the French GENCI/IDRIS-CINES centre for high-performance computing resources.

Acknowledgments: We thank Région Bretagne, Rennes Métropole, CNRS, Université de Rennes 1, the European Commission through the ERC-CoG 725184 MULTIPROSMM (project n. 725184) and ERC-AdG 267746 MolNanoMas (project no. 267746) and the ANR (ANR-13-BS07-0022-01) for financial support. B.L.G. and G.F.G. thank the French GENCI/IDRIS-CINES centre for high-performance computing resources.

Conflicts of Interest: The authors declare no conflict of interest. The founding sponsors had no role in the design of the study; in the collection, analyses, or interpretation of data; in the writing of the manuscript, or in the decision to publish the results.

\section{Abbreviations}

The following abbreviations are used in this manuscript:

$\begin{array}{ll}\mathrm{SMM} & \text { Single Molecule Magnet } \\ \mathrm{CH}_{2} \mathrm{Cl}_{2} & \text { dichloromethane } \\ \mathrm{tta}^{-} & \text {2-thenoyltrifluoroacetonate } \\ \mathrm{TTF} & \text { Tetrathiafulvalene } \\ \mathrm{HOMO} & \text { Highest Occupied Molecular Orbital } \\ \text { LUMO } & \text { Lowest Unoccupied Molecular Orbital } \\ \mathrm{ILCT} & \text { Intra-Ligand Charge Transfer } \\ \text { DFT } & \text { Density Functional Theory } \\ \text { TD-DFT } & \text { Time-Dependent Density Functional Theory } \\ \text { CASSCF } & \text { Complete Active Space Self-Consistent Field } \\ \text { RASSI-SO } & \text { Restricted Active Space State Interaction-Spin-Orbit }\end{array}$

\section{References}

1. Bryce, M.R. Tetrathiafulvalene as $\pi$-electron donors for intramolecular charge-transfer Materials. Adv. Mater. 1999, 11, 11-23. [CrossRef]

2. Yamada, J.; Sugimoto, T. TTF Chemistry: Fundamentals and Applications of Tetrathiafulvalene; Springer: Berlin, Germany, 2004.

3. Otsubo, T.; Takimiya, K. Recent synthetic advances of tetrathiafulvalene-based organic conductors. Bull. Chem. Soc. Jpn. 2004, 77, 43-58. [CrossRef]

4. Coronado, E.; Day, P. Magnetic molecular conductors. Chem. Rev. 2004, 104, 5419-5448. [CrossRef] 
5. Lorcy, D.; Bellec, N.; Fourmigué, M.; Avarvari, N. Tetrathiafulvalene-based group XV ligands: Synthesis, coordination chemistry and radical cation salts. Coord. Chem. Rev. 2009, 253, 1398-1438. [CrossRef]

6. Shatruk, M.; Ray, L. Ligands derived from tetrathiafulvalene: Building blocks for multifunctional materials. Dalton Trans. 2010, 39, 11105-11121. [CrossRef] [PubMed]

7. Batail, P. Introduction: Molecular conductors. Chem. Rev. 2004, 104, 4887-4890. [CrossRef]

8. Hansen, T.K.; Jørgensen, T.; Stein, P.C.; Becher, J. Crown ether derivatives of tetrathiafulvalene. J. Org. Chem. 1992, 57, 6403-6409. [CrossRef]

9. Beer, P.D.; Gale, P.A.; Chen, G.Z. Electrochemical molecular recognition: Pathways between complexation and signalling. J. Chem. Soc. Dalton Trans. 1999, 12, 1897-1910. [CrossRef]

10. Bernhardt, P.V.; Moore, E.G. Functionalized macrocyclic compounds: Potential sensors of small molecules and ions. Aust. J. Chem. 2003, 56, 239-258. [CrossRef]

11. Lu, H.Y.; Xu, W.; Zhang, D.Q.; Chen, C.F.; Zhu, D.B. A novel multisignaling optical-electrochemical chemosensor for anions based on tetrathiafulvalene. Org. Lett. 2005, 7, 4629-4632. [CrossRef]

12. McCall, K.L.; Morandeira, A.; Durrant, J.; Yellowlees, L.J.; Robertson, N. Characterisation of a ruthenium bipyridyl dye showing a long-lived charge-separated state on $\mathrm{TiO}_{2}$ in the presence of $\mathrm{I}^{-} / \mathrm{I}_{3}{ }^{-}$. Dalton Trans. 2010, 39, 4138-4145. [CrossRef]

13. Wenger, S.; Bouit, P.-A.; Chen, Q.L.; Teuscher, J.; Censo, D.D.; Humphry-Baker, R.; Moser, J.-E.; Delgado, J.L.; Martín, N.; Zakeeruddin, S.M.; et al. Efficient electron transfer and sensitizer regeneration in stable $\pi$-extended tetrathaifulvalene-sensitized solar cells. J. Am. Chem. Soc. 2010, 132, 5164-5169. [CrossRef]

14. Spaldin, N.A.; Fiebig, M. The renaissance of magnetoelectric multiferroics. Science 2005, 309, $391-392$. [CrossRef]

15. Eerenstein, W.; Mathur, N.D.; Scott, J.F. Multiferroic and magnetoelectric materials. Nature 2006, 442, 759-765. [CrossRef]

16. Train, C.; Gheorghe, R.; Krstic, V.; Chamoreau, L.-M.; Ovanesyan, N.S.; Rikken, G.L.J.A.; Gruselle, M.; Verdaguer, M. Strong magneto-chiral dichroism in enantiopure chiral ferromagnets. Nat. Mater. 2008, 7, 729-734. [CrossRef]

17. Ouahab, L.; Enoki, T. Multiproperty molecular materials: TTF-based conducting and magnetic molecular materials. Eur. J. Inorg. Chem. 2004, 933-941. [CrossRef]

18. Kobayashi, A.; Fujiwara, E.; Kobayashi, H. Single-component molecular metals with extended-TTF dithiolate ligands. Chem. Rev. 2004, 104, 5243-5264. [CrossRef]

19. Enoki, T.; Miyasaki, A. Magnetic TTF-based charge-transfer complexes. Chem. Rev. 2004, 104, 5449-5478. [CrossRef]

20. Pointillart, F.; Golhen, S.; Cador, O.; Ouahab, L. $3 d$ and $4 d$ coordination complexes and coordination polymers involving electroactive tetrathiafulvalene containing ligands. Comptes Rendus Chimie 2013, 16, 679-687. [CrossRef]

21. Pointillart, F.; Le Gal, Y.; Golhen, S.; Cador, O.; Ouahab, L. First paramagnetic 4d transition-metal complex with a redox-active tetrathiafulvalene derivative, [Ru(salen) $\left.\left(\mathrm{PPh}_{3}\right)(\mathrm{TTF}-\mathrm{CH}=\mathrm{CH}-\mathrm{Py})\right] \mathrm{BF}_{4}$ [salen ${ }^{2-}=N, N^{\prime}$-Ethan-1,2-diylbis(salicylidenamine), $\mathrm{PPh}_{3}=$ triphenylphosphine, TTF-CH=CH-Py = 4-(2-tetrathiafulvalenylethenyl)pyridine]. Inorg. Chem. 2008, 47, 9730-9732.

22. Rabaca, S.; Almeida, M. Dithiolene complexes containing N coordinating groups and corresponding tetrathiafulvalene donors. Coord. Chem. Rev. 2010, 254, 1493-1508. [CrossRef]

23. Pointillart, F.; Golhen, S.; Cador, O.; Ouahab, L. Paramagnetic 3d coordination complexes involving redox-active tetrathiafulvalene derivatives: An efficient approach to elaborate multi-properties materials. Dalton Trans. 2013, 42, 1949-1960. [CrossRef]

24. Huang, Y.-D.; Huo, P.; Shao, M.-Y.; Yin, J.-X.; Shen, W.-C.; Zhu, Q.-Y.; Dai, J. A new type of charge-transfer salts based on tetrathiafulvalene-tetracarboxylate coordination polymers and methyl viologen. Inorg. Chem. 2014, 53, 3480-3487. [CrossRef]

25. Faulkner, S.; Burton-Pye, B.P.; Khan, T.; Martin, L.R.; Wray, S.D.; Skabara, P.J. Interaction between tetrathiafulvalene carboxylic acid and ytterbium DO3A: Solution state self-assembly of a ternary complex which is luminescent in the near IR. Chem. Commun. 2002, 16, 1668-1669. [CrossRef]

26. Pope, S.J.A.; Burton-Pye, B.P.; Berridge, R.; Khan, T.; Skabara, P.; Faulkner, S. Self-assembly of luminescent ternary complexes between seven-coordinate lanthanide(III) complexes and chromophore bearing carboxylates and phosphonates. Dalton Trans. 2006, 2907-2912. [CrossRef] 
27. Pointillart, F.; Le Gal, Y.; Golhen, S.; Cador, O.; Ouahab, L. $4 f$ Gadolinium(III) complex involving tetrathiafulvalene-amido-2-pyrimidine-1-oxide as a ligand. Inorg. Chem. 2009, 48, 4631-4633. [CrossRef]

28. Pointillart, F.; Le Guennic, B.; Golhen, S.; Cador, O.; Maury, O.; Ouahab, L. High nuclearity complexes of lanthanide involving tetrathiafulvalene ligands: Structural, magnetic, and photophysical properties. Inorg. Chem. 2013, 52, 1610-1620. [CrossRef]

29. Woodruff, D.N.; Winpenny, R.E.P.; Layfield, R.A. Lanthanide single-molecule magnets. Chem. Rev. 2013, 113, 5110-5148. [CrossRef]

30. Pointillart, F.; Cador, O.; Le Guennic, B.; Ouahab, L. Uncommon lanthanide ions in purely 4f single molecule magnets. Coord. Chem. Rev. 2017, 346, 150-175. [CrossRef]

31. Zhang, P.; Guo, Y.-N.; Tang, J. Recent advances in dysprosium-based single molecule magnets: Structural overview and synthetic strategies. Coord. Chem. Rev. 2013, 257, 1728-1763. [CrossRef]

32. Liddle, S.T.; van Slageren, J. Improving f-element single molecule magnets. Chem. Soc. Rev. 2015, 44, 6655-6669. [CrossRef]

33. Meng, Y.-S.; Jiang, S.-D.; Wang, B.-W.; Gao, S. Understanding the magnetic anisotropy toward single-ion magnets. Acc. Chem. Res. 2016, 49, 2381-2389. [CrossRef]

34. Liu, J.-L.; Chen, Y.-C.; Tong, M.-L. Symmetry strategies for high performance lanthanide-based single-molecule magnets. Chem. Soc. Rev. 2018, 47, 2431-2453. [CrossRef]

35. Gupta, S.K.; Murugavel, R. Enriching lanthanide single-ion magnetism through symmetry and axiality. Chem. Commun. 2018, 54, 3685-3696. [CrossRef]

36. Zhu, Z.; Guo, M.; Li, X.-L.; Tang, J. Molecular magnetism of lanthanide: Advances and perspectives. Coord. Chem. Rev. 2019, 378, 350-364. [CrossRef]

37. Guo, F.-S.; Bar, A.K.; Layfield, R.A. Main group chemistry at the interface with molecular magnetism. Chem. Rev. 2019. [CrossRef]

38. Gatteschi, D.; Sessoli, R.; Villain, J. Molecular Nanomagnets; Oxford University Press: New York, NY, USA, 2006.

39. Bogani, L.; Wernsdorfer, W. Molecular spintronics using single-molecule magnets. Nat. Mater. 2008, 7, 179-186. [CrossRef]

40. Mannini, M.; Pineider, F.; Sainctavit, P.; Danieli, C.; Otero, E.; Sciancalepore, C.; Talarico, A.-M.; Arrio, M.-A.; Cornia, A.; Gatteschi, D.; et al. Magnetic memory of a single-molecule quantum magnet wired to a gold surface. Nat. Mater. 2009, 8, 194-197. [CrossRef]

41. Leuenberger, M.N.; Loss, D. Quantum computing in molecular magnets. Nature 2001, 410, 789-793. [CrossRef]

42. Lehmann, J.; Gaita-Arino, A.; Coronado, E.; Loss, D. Spin qubits with electrically gated polyoxometallate molecules. Nat. Nanotechnol. 2007, 2, 312-317. [CrossRef]

43. Ganzhorn, M.; Klyatskaya, S.; Ruben, M.; Wernsdorfer, W. Strong spin-phonon coupling between a single-molecule magnet and a carbon nanotube nanoelectromechanical system. Nat. Nanotechnol. 2013, 8, 165-169. [CrossRef]

44. Gao, F.; Cui, L.; Liu, W.; Hu, L.; Zhong, Y.-W.; Li, Y.-Z.; Zuo, J.-L. Seven-coordinate lanthanide sandwich-type complexes with a tetrathiafulvalene-fused schiff base ligand. Inorg. Chem. 2013, 52, 11164-11172. [CrossRef]

45. Pointillart, F.; Le Guennic, B.; Maury, O.; Golhen, S.; Cador, O.; Ouahab, L. Lanthnaide dinuclear complexes involving tetrathiafulvalene-3-pyridine-N-oxide ligand: Semiconductor radical salt, magnetic, and photophysical studies. Inorg. Chem. 2013, 52, 1398-1408. [CrossRef]

46. Pointillart, F.; Jung, J.; Berraud-Pache, R.; Le Guennic, B.; Dorcet, V.; Golhen, S.; Cador, O.; Maury, O.; Guyot, Y.; Decurtins, S.; et al. Luminescence and single-molecule magnet behavior in lanthanide complexes invlving a tetrathiafulvalene-fused dipyridophenazine ligand. Inorg. Chem. 2015, 54, 5384-5397. [CrossRef]

47. Gao, F.; Zhang, X.-M.; Cui, L.; Deng, K.; Zeng, Q.-D.; Zuo, J.-L. Tetrathiafulvalene-supported triple-decker phthalocyaninato dysprosium(III) complex: Synthesis, properties and surface assembly. Sci. Rep. 2014, 4, 5928-5935. [CrossRef]

48. Pointillart, F.; Le Guennic, B.; Golhen, S.; Cador, O.; Maury, O.; Ouahab, L. A redox-active luminescent ytterbium based single molecule magnet. Chem. Commun. 2013, 49, 615-617. [CrossRef]

49. Soussi, K.; Jung, J.; Pointillart, F.; Le Guennic, B.; Lefeuvre, B.; Golhen, S.; Cador, O.; Guyot, Y.; Maury, O.; Ouahab, L. Magnetic and photo-physical inverstigations into Dy ${ }^{\mathrm{III}}$ and $\mathrm{Yb}^{\mathrm{III}}$ complexes involving tetrathiafulvalene ligand. Inorg. Chem. Front. 2015, 2, 1105-1117. [CrossRef] 
50. Pointillart, F.; Le Guennic, B.; Cador, O.; Maury, O.; Ouahab, L. Lanthanide ion and tetrathiafulvalene-based ligand as a "magic" couple toward luminescence, single molecule magnets, and magnetostructural correlations. Acc. Chem. Res. 2015, 48, 2834-2842. [CrossRef]

51. Feng, M.; Pointillart, F.; Lefeuvre, B.; Dorcet, V.; Golhen, S.; Cador, O.; Ouahab, L. Multiple single-molecule magnet behaviors in dysprosium dinuclear complexes involving a multiple functionalized tetrathiafulvalene-based ligand. Inorg. Chem. 2015, 54, 4021-4028. [CrossRef]

52. Speed, S.; Feng, M.; Fernandez-Garcia, G.; Pointillart, F.; Lefeuvre, B.; Riobé, F.; Golhen, S.; Le Guennic, B.; Totti, F.; Guyot, Y.; et al. Lanthanide complexes involving multichelating TTF-based ligands. Inorg. Chem. Front. 2017, 4, 604-617. [CrossRef]

53. Lefeuvre, B.; Galangau, O.; Flores Gonzalez, J.; Montigaud, V.; Dorcet, V.; Ouahab, L.; Le Guennic, B.; Cador, O.; Pointillart, F. Field-induced dysprosium single-molecule magnet based on a redox-active fused 1,10-phenantroline bridging triad. Front. Chem. 2018, 6, 552-562. [CrossRef]

54. Pointillart, F.; Ou-Yang, J.-K.; Fernandez Garcia, G.; Montigaud, V.; Flores Gonzalez, J.; Marchal, R.; Favereau, L.; Totti, F.; Crassous, J.; Cador, O.; et al. Tetrathiafulvalene-based helicene ligand in the design of a dysprosium field-induced single-molecule magnet. Inorg. Chem. 2019, 58, 52-56. [CrossRef]

55. Pointillart, F.; Le Gal, Y.; Golhen, S.; Cador, O.; Ouahab, L. Binuclear gadolinium(III) coordination complex based on bridging tetrathiafulvalenecarboxylate radical cations. Chem. Commun. 2009, 3777-3779. [CrossRef]

56. Pointillart, F.; Le Guennic, B.; Golhen, S.; Cador, O.; Ouahab, L. Slow magnetic relaxation in radical cation tetrathiafulvalene-based lanthanide(III) dinuclear complexes. Chem. Commun. 2013, 49, 11632-11634. [CrossRef]

57. Wang, H.-Y.; Ge, J.-Y.; Hua, C.; Jiao, C.-Q.; Wu, Y.; Leong, C.F.; D’Alessandro, D.M.; Liu, T.; Zuo, J.-L. Photo-and electronically switchable spin-crossover iron(II) metal-organic frameworks based on a tetrathiafulvalene ligand. Angewandte Chemie Int. Ed. 2017, 56, 5465-5470. [CrossRef]

58. Su, J.; Hu, T.-H.; Murase, R.; Wang, H.-Y.; D'Alessandro, D.M.; Kurmoo, M.; Zuo, J.-L. Redox activities of metal-organic frameworks incorporating rare-earth metal chains and tetrathiafulvalene linkers. Inorg. Chem. 2019, 58, 3698-3706. [CrossRef]

59. Da Cunha, T.T.; Jung, J.; Boulon, M.-E.; Campo, G.; Pointillart, F.; Pereira, C.L.M.; Le Guennic, B.; Cador, O.; Bernot, K.; Pineider, F.; et al. Magnetic poles determinations and robustness of memory effect upon solubilization in a Dy ${ }^{\mathrm{III}}$-based single ion magnet. J. Am. Chem. Soc. 2013, 135, 16332-16335. [CrossRef]

60. Pointillart, F.; Bernot, K.; Golhen, S.; Le Guennic, B.; Guizouarn, T.; Ouahab, L.; Cador, O. Magnetic Memory in an Isotopically Enriched and Magnetically Isolated Mononuclear Dysprosium Complex. Angewandte Chemie Int. Ed. 2015, 54, 1504-1507. [CrossRef]

61. Tesi, L.; Salman, Z.; Cimatti, I.; Pointillart, F.; Bernot, K.; Mannini, M.; Sessoli, R. Isotope effects on the spin dynamics of single-molecule magnets probed using muon spin spectroscopy. Chem. Commun. 2018, 54, 7826-7829. [CrossRef]

62. Flores Gonzalez, J.; Pointillart, F.; Cador, O. Hyperfine coupling and slow magnetic relaxation in isotopically enriched Dy ${ }^{\mathrm{III}}$ mononuclear single-molecule magnets. Inorg. Chem. Front. 2019, 6, 1081-1086. [CrossRef]

63. Llunell, M.; Casanova, D.; Cirera, J.; Bofill, J.M.; Alemany, P.; Alvarez, S. SHAPE (Version 2.1); Electronic Structure Group: Barcelona, Spain, 2013.

64. Lu, W.; Zhang, Y.; Dai, J.; Zhu, Q.-Y.; Bian, G.-Q.; Zhang, D.-Q. A Radical-radical and metal-metal coupling tetrathiafulvalene derivative in which organic radicals directly coordinate to $\mathrm{Cu}^{\mathrm{II}}$ ions. Eur. J. Inorg. Chem. 2006, 1629-1634. [CrossRef]

65. Inoue, M.B.; Inoue, M.; Bruck, M.A.; Fernando, Q. Structure of bis(ethylenedithio)tetrathiafulvalenium tribromodicuprate $(\mathrm{I}),(\mathrm{BEDT}-\mathrm{TTF}+) \mathrm{Cu}_{2} \mathrm{Br}_{3}$ : Coordination of the organic radical cation to the metal ions. J. Chem. Soc. Chem. Commun. 1992, 515. [CrossRef]

66. Liu, S.-X.; Ambrus, C.; Dolder, S.; Neels, A.; Decurtins, S. A dinuclear Ni(II) complex with two types of intramolecular magnetic couplings: $\mathrm{Ni}(\mathrm{II})-\mathrm{Ni}(\mathrm{II})$ and $\mathrm{Ni}(\mathrm{II})-\mathrm{TTF}^{+}$. Inorg. Chem. 2006, 45, 9622-9624. [CrossRef]

67. Jia, C.; Liu, S.-X.; Tanner, C.; Leiggener, C.; Neels, A.; Sanguinet, L.; Levillain, E.; Leutwyler, S.; Hauser, A.; Decurtins, S. An experimental and computational study on intramolecular charge transfer: A tetrathiafulvalene-fused dipyridophenazine molecule. Chem. Eur. J. 2007, 13, 3804-3812. [CrossRef] 
68. Cosquer, G.; Pointillart, F.; Le Guennic, B.; Le Gal, Y.; Golhen, S.; Cador, O.; Ouahab, L. 3d4f heterobimetallic dinuclear and tetranuclear complexes involving tetrathiafulvalene as ligands: $X$-ray structures and magnetic and photophysical investigations. Inorg. Chem. 2012, 51, 8488-8501. [CrossRef]

69. Takamatsu, S.; Ishikawa, T.; Koshihara, S.-Y.; Ishikawa, N. Significant increase of the barrier energy for magnetization reversal of a single-4f-ionic single-molecule magnet by a longitudinal contraction of the coordination space. Inorg. Chem. 2007, 46, 7250-7252. [CrossRef]

70. Gonidec, M.; Stephen Davies, E.; McMaster, J.; Amabilino, D.B.; Veciana, J. Probing the magnetic properties of three interconvertible redox states of a single-molecule magnet with magnetic circular dichroism spectroscopy. J. Am. Chem. Soc. 2010, 132, 1756-1757. [CrossRef]

71. Dolinar, B.S.; Gomez-Coca, S.; Alexandropoulos, D.I.; Dunbar, K.R. An air stable radical-bridged dysprosium single molecule magnet and its neutral counterpart: Redox switching of magnetic relaxation dynamics. Chem. Commun. 2017, 53, 2283-2286. [CrossRef]

72. Cosquer, G.; Pointillart, F.; Golhen, S.; Cador, O.; Ouahab, L. Slow magnetic relaxation in condensed versus dispersed dysprosium(III) mononuclear complexes. Chem. Eur. J. 2013, 19, 7895-7903. [CrossRef]

73. Vooshin, A.I.; Shavaleev, N.M.; Kazakov, V.P. Chemiluminescence of praseodymium (III), neodymium (III) and ytterbium (III) $\beta$-diketonates in solution excited from 1,2-dioxetane decomposition and singlet-singlet energy transfer from ketone to rare-earth $\beta$-diketonate. J. Lumin. 2000, 91, 49-58. [CrossRef]

74. Frisch, M.J.; Trucks, G.W.; Schlegel, H.B.; Scuseria, G.E.; Robb, M.A.; Cheeseman, J.R.; Scalmani, G.; Barone, V.; Mennucci, B.; Petersson, G.A.; et al. Gaussian 09 Revision, A.02; Gaussian Inc.: Wallingford, CT, USA, 2009.

75. Perdew, J.P.; Burke, K.; Ernzerhof, M. Generalized gradient approximation made simple. Phys. Rev. Lett. 1996, 77, 3865-3868. [CrossRef]

76. Adamo, C.; Barone, V. Toward reliable density functional methods without adjustable parameters: The PBE0 model. J. Chem. Phys. 1999, 110, 6158-6170. [CrossRef]

77. Dolg, M.; Stoll, H.; Preuss, H. A combination of quasirelativistic pseudopotential and ligand field calculations for lanthanoid compounds. Theor. Chim. Acta. 1993, 85, 441-450. [CrossRef]

78. Weigend, F.; Ahlrichs, R. Balanced basis sets of split valence, triple zeta valence and quadruple zeta valence quality for H to Rn: Design and assessment of accuracy. Phys. Chem. Chem. Phys. 2005, 7, 3297-3305. [CrossRef]

79. Tomasi, J.; Mennucci, B.; Cammi, R. Quantum mechanical continuum solvation models. Chem. Rev. 2005, 105, 2999-3093. [CrossRef]

80. Cossi, M.; Barone, V. Time-dependent density functional theory for molecules in liquid solutions. J. Chem. Phys. 2001, 115, 4708-4717. [CrossRef]

81. Improta, R.; Barone, V.; Scalmani, G.; Frisch, M.J.A. A state-specific polarizable continuum model time dependent density functional theory method for excited state calculations in solution. J. Chem. Phys. 2006, 125, 054103-054109. [CrossRef]

82. Allouche, A.R. Gabedit-a graphical user interface for computational chemistry softwares. J. Comput. Chem. 2011, 32, 174-182. [CrossRef]

83. Aquilante, F.; Autschbach, J.; Carlson, R.K.; Chibotaru, L.F.; Delcey, M.G.; De Vico, L.; Fernández Galván, I.; Ferré, N.; Frutos, L.M.; Gagliardi, L.; et al. MOLCAS 8: New capabilities for multiconfigurational quantum chemical calculations across the periodic table. J. Comput. Chem. 2016, 37, 506-541. [CrossRef]

84. Roos, B.O.; Taylor, P.R.; Siegbahn, P.E.M. A complete active space SCF method (CASSCF) using a density matrix formulated super-CI approach. Chem. Phys. 1980, 48, 157-173. [CrossRef]

85. Malmqvist, P.Å.; Roos, B.O.; Schimmelpfennig, B. The restricted active space (RAS) state interaction approach with spin-orbit coupling. Chem. Phys. Lett. 2002, 357, 230-240. [CrossRef]

86. Malmqvist, P.-Å.; Roos, B.O. The CASSCF state interaction method. Chem. Phys. Lett. 1989, 155, $189-194$. [CrossRef]

87. Chibotaru, L.F.; Ungur, L. Ab initio calculation of anisotropic magnetic properties of complexes I. Unique definition of pseudospin Hamiltonians and their derivation. J. Chem. Phys. 2012, 137, 064112-064122. [CrossRef]

88. Chibotaru, L.; Ungur, L.; Soncini, A. The origin of nonmagnetic kramers doublets in the ground state of dysprosium triangles: Evidence for a toroidal magnetic moment. Angewandte Chemie Int. Ed. 2008, 47, 4126-4129. [CrossRef] 
89. Aquilante, F.; Malmqvist, P.-Å.; Pedersen, T.B.; Ghosh, A.; Roos, B.O. Cholesky decomposition-based multiconfiguration second-order perturbation theory (CD-CASPT2): Application to the spin-state energetics of CoIII(diiminato)(NPh). J. Chem. Theory Comput. 2008, 4, 694-702. [CrossRef]

90. Roos, B.O.; Lindh, R.; Malmqvist, P.A.; Veryazov, V.; Widmark, P.O. Main group atoms and dimers studied with a new relativistic ANO Basis Set. J. Phys. Chem. A 2004, 108, 2851-2858. [CrossRef]

91. Roos, B.O.; Lindh, R.; Malmqvist, P.-A.; Veryazov, V.; Widmark, P.-O. New relativistic ANO Basis Sets for transition metal atoms. J. Phys. Chem. A 2005, 109, 6575-6579. [CrossRef]

92. Roos, B.O.; Lindh, R.; Malmqvist, P.; Veryazov, V.; Widmark, P.O.; Borin, A.C. New relativistic atomic natural orbital basis sets for lanthanide atoms with applications to the Ce diatom and LuF3. J. Phys. Chem. A 2008, 112, 11431-11435. [CrossRef]

(C) 2019 by the authors. Licensee MDPI, Basel, Switzerland. This article is an open access article distributed under the terms and conditions of the Creative Commons Attribution (CC BY) license (http://creativecommons.org/licenses/by/4.0/). 